\title{
THE
}

2013

\section{Lean Systems: Soft OR in practice}

Satya S. Chakravorty

Douglas N. Hales

University of Rhode Island, dhales@uri.edu

Follow this and additional works at: https://digitalcommons.uri.edu/cba_facpubs

The University of Rhode Island Faculty have made this article openly available.

Please let us know how Open Access to this research benefits you.

This is a pre-publication author manuscript of the final, published article.

Terms of Use

This article is made available under the terms and conditions applicable towards Open Access

Policy Articles, as set forth in our Terms of Use.

\section{Citation/Publisher Attribution}

Chakravorty, S. S. \& Hales, D. N. Lean Systems: Soft OR in practice. OR Insight, 26, 149-166.

Available at: http://dx.doi.org/10.1057/ori.2012.15

This Article is brought to you for free and open access by the College of Business at DigitalCommons@URI. It has been accepted for inclusion in College of Business Faculty Publications by an authorized administrator of DigitalCommons@URI.For more information, please contact digitalcommons-group@uri.edu. 


\title{
Lean System: Soft OR in Practice
}

\author{
Satya S. Chakravorty \\ Department of Management and Entrepreneurship \\ Michael J. Coles College of Business \\ Kennesaw State University \\ 1000 Chastain Rd. \\ Kennesaw GA 30144-5591, USA \\ Tel.: 770.423 .6582 \\ Fax: 770.423 .6606 \\ Email:schakrav@kennesaw.edu \\ Douglas N. Hales \\ College of Business Administration \\ University of Rhode Island \\ 321 Ballentine Hall \\ 7 Lippitt Road \\ Kingston, RI 02881-0802, USA \\ Tel.: 401.874 .7882 \\ Fax: 401.874 .4312 \\ Email:dhales@uri.edu
}

\begin{abstract}
Lean implementation involves eliminating all forms of waste (e.g., defects or overproduction) and consists of many improvement strategies or systems, such as mistake-proofing (Poka-Yoke) and Single Minute Exchange of Die (SMED, a.k.a. quick changeover). The purpose of this study is to discuss a successful Lean or waste elimination initiative for a building products company. Specifically, this study describes how mistake proofing and quick changeover systems were implemented using soft OR practices or Soft System's Methodology (SSM). Essentially, SSM consisted of four sequential stages, namely [1] problem identification, [2] basic approaches to improvement, [3] making plans for improvement, and [4] translating improvement plans into reality. This study contributes in two ways. First, relevant for practicing managers, this study shows that at the core of Lean is soft OR practices. Second, relevant for academicians, this study provides directions for future research.
\end{abstract}

Keywords: Soft OR; Lean; Waste Elimination 


\section{Lean System: Soft OR in Practice}

\section{Introduction}

Lean system's role in driving operational excellence is well known. Widely recognized as originating from Toyota, Lean implementation involves eliminating all forms of waste (e.g., defects or overproduction) and consists of many improvement strategies or systems (Chakravorty, 2009). Two such systems are mistake-proofing (Poka-Yoke) and Single Minute Exchange of Die (SMED, a.k.a. quick changeover). Mistake proofing systems prevent errors or human forgetfulness from turning into defects, which eliminates the waste of defects (Shingo, 1986). Similarly, quick changeover systems reduce machine setup time, which in turn reduces the size of the production runs, thus eliminating the waste of overproduction (Shingo, 1985). Over the years, these systems are heavily promoted by practitioners' books (e.g., Womack and Jones, 2003), the Shingo Prize for Operational Excellence ${ }^{1}$, American Society of Quality ${ }^{2}$, and a plethora of consulting companies ${ }^{3}$. To date, we have found no study explaining how to systematically implement these systems in real-world companies, or why these systems work to improve performance.

This study describes a successful Lean implementation in a building products company (BPC). Specifically, this study shows how mistake proofing and quick changeover systems were implemented using soft OR practices through Soft System's Methodology (SSM). Essentially, SSM consists of four sequential stages, namely [1] problem identification, [2] basic approaches to improvement, [3] making plans for improvement, and [4] translating improvement plans into reality. This study contributes in two ways. First, relevant for practicing managers, this study shows that at the core of Lean implementation is soft OR practices. Second, relevant for academicians, this study provides directions for future research to enhance the science and practice of improvements. In the next section we provide a discussion of soft OR practices and SSM. We highlight the importance of soft OR practices in driving operational excellence programs in world class companies. Following a description of the company, we present our implementation experience. Finally, we provide implications for the implementation and directions for future research. 


\section{Literature Review}

\subsection{Soft OR Practices}

In order to improve operations, a range of analytical tools involving quantitative and qualitative approaches are often utilized (e.g., Mingers, 2011; Paucar-Caceres, 2010; Chakravorty and Hales, 2008; Reisman and Oral, 2005; Heyer, 2004; Pidd, 2003; Beasley, 2002). Quantitative approaches or hard OR practices include Linear Programming, Queuing Theory, and Statistical Analysis. Qualitative approaches or soft OR practices include Strategic Options Development and Analysis (SODA), Viable Systems Model (VSM), and Soft System's Methodology (SSM). While there are many steps of SSM (e.g., Checkland, 1999), essentially SSM consists of four stages. The first stage is problem identification or opportunity delineation. The second stage deals with information-gathering. Typically, the next stage deals with issues of generating ideas and evaluating possible solutions. The last stage involves developing a plan to implement the ideas and putting them into practice.

World class companies (e.g., Toyota) routinely apply SSM to implement Lean. According to Chakravorty (2009), Toyota implements a four-stage process or A3 report to drive and document the results of improvement activities. In describing Toyota's approach to improvements, Spear and Bowman (1999, p.98) wrote that Toyota requires:

\footnotetext{
“... a detailed assessment of the current state of affairs and a plan for improvement that is, in effect, an experimental test of the proposed changes. With anything less than such scientific rigor, change at Toyota will amount to little more than random trial and error - a blindfold walk through life."
}

There are several books (e.g., Liker, 2004) which describe Lean systems in Toyota. However, considered to be co-developers of Toyota's production system, the early works of Taiichi Ohno and Shigeo Shingo stand out. Ohno, (1988) identified seven categories of waste: waste from defects, overproduction, inventory, motion, processing, waiting, and transportation. Shingo in many of his books described improvement strategies or systems to eliminate waste (Shingo, 1985, Shingo, 1986, Shingo, 1987, Shingo, 1988).

\subsection{Shingo Version of Soft System's Methodology}

Shingo's version of Soft System's Methodology is (SSM) is delineated in two of his books (Shingo, 1987; Shingo, 1988). It is important to note that Checkland (1999)'s SSM consists of seven steps and they are: (1) \& (2) confronting the problem situation, (3) developing root 
definitions, (4) building a conceptual model, (5) comparing models with the real world, (6) identifying changes, (7) taking the action. Basically, Checkland's step 1, 2, and 3 are embedded in Shingo's stage 1, and likewise; Checkland's steps 4 and 5 are included in Shingo's stage 2. The central theme behind Shingo's version of SSM is finding and eliminating all forms of waste by using a sequential four-stage process.

\section{Stage 1: Problem Identification}

The objective of this stage is to identify problems by persistently challenging the existing system. The system description or root definition describes input, transformation process and its owner, and output. The challenge at this stage is to discover problems where one thinks none exist. To illustrate his point Shingo (1987) used an example of a banana to distinguish between the parts of a job that add value and those that don't. He argued that the banana skin only adds cost, and it is the fruit that adds value. According to Shingo, (1987, p.19):

\footnotetext{
"Just as no one really resents paying for the banana skins, we do not question what goes on in the workplace. Even when most of the work only increases cost and little is done to increase value, we become habituated to the situation, satisfied that a good job is being done if the work is performed conscientiously. Frequently we do not perceive the intrinsic value of the work. We must take another hard look at work and recognize what is fruit and what is skin."
}

\section{Stage 2: Basic Approaches to Improvement}

The objective of this stage is to develop a thorough understanding by compiling relevant information about the problem and its existing conditions. The information should be gathered using quantitative and qualitative methods such as published materials (quality reports, catalogues), interviews and discussion with managers and workers, observation of machines and process, and impressions, which include feelings and insights. According to Shingo (1987), through rigorous examination of information or building conceptual models and comparing them with real world models, one can grasp the truth underlying a problem.

\section{Stage 3: Making Plans for Improvement}

This stage has two objectives. The first objective is to generate a number of new solution ideas for the identified problem without immediately evaluating (or criticizing) the ideas. Once ideas have been generated, the next objective is to evaluate the ideas. The evaluation process includes carefully determining the strengths and weakness of each idea, modifying ideas to develop another idea, and, if necessary, discarding ideas that are no longer necessary. Shingo (1987) 
cautions that the people should not be quick in discarding ideas; instead, they should try harder, more positive ways to develop ideas for implementation.

\section{Stage 4: Translating Improvement Plans into Reality}

The purpose of this stage is to put the ideas into practice. In order to put ideas into practice, a plan needs to be in place to overcome people's resistance to change. People are commonly prone to inertia, rather than to generating the energy that changes require, and often prefer to continue their old ways of working. Therefore, extraordinary efforts are necessary to break people into new ways of working (Shingo, 1987). To convince shop workers, first put the initial idea into action, and then demonstrate the benefits from such an idea to everyone else. By making the benefits visible, many people can be persuaded that improvements are really possible (Shingo, 1987).

\section{The Company}

We conducted this study in a building product company (BPC), a manufacturer and supplier of residential and light commercial building products located in Georgia, Alabama, and Tennessee. The implementation effort was initiated because of the company's worsening performance in the market. The BPC had the highest quoted production lead time s among its major competitors. Customer returns due to quality issues had risen from $4 \%$ to $15 \%$ in the preceding six months. This led to extensive rework, putting pressure on purchasing for material and on production for a priority schedule. Poor performance was forcing many of the company's customers to seek other suppliers. Given the highly competitive environment of the market, this was a serious problem for the company. Managers wanted to implement Lean, and apply soft OR practices, because they believed the practices were simple to understand, and that the program could eventually be driven from the lowest levels of the company.

\section{Lean Implementation}

\subsection{Description of the Implementation}

The redesign effort was initiated by the BPC's executive team which consisted of the President, the VP of Marketing, VP of Production, VP of Purchasing, VP of Human Resources, and the VP of Accounting. The general consensus was that customer returns due to quality issues and longer lead-times were not due to a single problem, but were the result of cross-functional processes 
involving mistakes in many departments, such as Oder writing, production, and shipping. It was believed that mistakes were then amplified as work progressed through the system. The executive team decided to develop a cross-functional improvement team, called the C-FIT, comprised of researchers, managers, and workers. In addition to the researchers, two members were chosen from Inside Sales and Order Writing, three members from the production department, and two members from Shipping. C-FIT was responsible developing a charter for the improvement initiatives, a timeline for the implementation, and a budget. Initially, C-FIT interviewed personnel (managers, supervisors, and workers) from different departments and by reviewing customer complaint reports, order processing, manufacturing and quality reports, and shipping reports. The initial assessment confirmed that the deteriorating performance was due to many wasteful activities at each stage of the order fulfillment system.

Following the initial assessment, C-FIT diligently worked on the Lean training program for the workers and the managers. C-FIT was aware the education level on the shop floor was low. Most workers had high school degrees and some managers had college degrees. The training session included simple and easy to understand concepts of Lean system - i.e., seven categories of waste, mistake proofing, quick changeover, and the four steps of SSM. The researchers delivered the training sessions in two-hour segments and provided illustrations, anecdotes, stories, and examples to keep the interest of the workers and managers. As a follow up of the training, the researchers guided the managers and worker through many applications of SSM to develop mistake proofing or quick changeover systems.

The next step involved value stream mapping the order fulfillment system in order to understand the complex flow of information and material. They found that the existing order fulfillment system consisted of four distinct steps. Step 1 was order processing by inside sales, outside sales or directly from customers, and writers who manually generate shop orders. They also release a "shipping ticket" to the shipping department with date and time of delivery. Step 2 consisted of separating the production orders by type, i.e. by doors, windows, etc. Many orders received components from all shops. Step 3 consisted of locating an order using the shipping ticket, loading and transporting the order to a job site, and unloading the order at the job site. Step 4 consisted of installing the production units at the jobsite. While performing value stream mapping, C-FIT found examples of wasteful activities, such as outdated information on existing 
customers and incomplete information on new customers. This delayed many orders from being processed. C-FIT also found redundant procedures, such as duplicate and confusing paperwork, that in previous years had been initiated to help catch inconsistencies in customer orders because many orders would change by the time the shop order was cut. Because the tooling for machine setups was not organized before a line was shut down, equipment set idle waiting to be setup, creating a loss of capacity. Human errors on purchase orders and on incoming materials, etc. were not caught because the redundancies no longer existed.

C-FIT documented many wasteful activities throughout the order fulfillment system and had difficulty in prioritizing waste elimination projects. Considering overall improvement objectives, they identified 23 potential improvement projects. Because of limited resources, all the improvement projects could not be implemented simultaneously. After deliberations, and with consensus, C-FIT agreed to prioritize the improvement projects using two parameters: reduced lead time and improved quality. The lead times could be reduced through faster response times, reduced inventory (raw material, work in process, and finished goods), better utilization of bottlenecks. Improved quality would be judged through a reduction in customer returns. Using the two parameters, C-FIT prioritized improvement projects based on those with the strongest support (i.e. those projects most mentioned by workers and managers). The priorities were presented to the executive team for input and approval.

Using the priority list, a detailed implementation was developed consisting of five major activities. First, lower-level implementation teams consisting of 4 to 5 shop workers were established to carry out the implementation on the shop floor. Second, the researchers assisted the teams to become completely familiar with the shop and its operations. Third, the team verbalized possible problem statements. (Initially, when a problem statement was first written, there was no clear agreement among the team members for its cause.) Fourth, a room was secured close to the shop floor for the researchers to conduct training, and workers to meet to discuss ways to identify and solve the problems. Fifth, the training was delivered by a researcher in an interactive manner, using presentation slides with audio and video enhancements.

C-FIT identified "improvement champions" in each area who were responsible for leading shop floor efforts, and who held a series of formal and informal meetings with workers. The purpose 
was to prepare the workers for change and to ensure active participation during the implementation. C-FIT found that, initially, when the implementation teams were solving relatively easy problems, problems were clearly identified, and the SSM progressed sequentially. Issue resolutions were smooth, teams behaved in a predictable and rational manner, and learning was fun. The rate of improvement showed an upward trend and the return on investment was high. However, later, when the implementation teams were solving relatively difficult problems, the problems were not clearly identified, the SSM progressed haphazardly. See Appendix I for examples (Problem I, II, III, and IV) of mistake proofing and quick changeovers implementations. While solving Problem I at Stage 2, two additional problems (Problem II and III) were discovered which required SSM application. Problem II started from Stage 2 but Problem III started from Stage 1. While solving Problem II at Stage 4, one additional problem (Problem IV) was found requiring SSM application from Stage 2 (see Figure 1). Issue resolutions were rough. The teams behaved in an unpredictable and apparently irrational manner and learning was not fun for the workers. C-FIT had to stabilize the situation, emphasize that it takes a longer time to solve difficult problems, and that patience among team members was needed. While improvements did continue, the rate of improvements flattened out, and the return on investment was lower. This variation in time is best described in one of our research log entries:

"While addressing difficult problems with no clear solutions, the members of the implementation team interacted among themselves through intense deliberation with members vehemently arguing their points. This created anger, frustration, and resentment among the members of the team - inciting emotional outbursts on several occasions. There were major differences of opinions on either the source(s) or on the solution of the problem or both. Many of the solutions were too expensive to try randomly; therefore, they had to choose only a few to examine further. When the team interacted with different departments to apply SSM, there was rarely consensus. This led to a serious breakdown of communication between the team and the departments. In fact, many times departmental managers openly vocalized their disagreements, questioning upper management's commitment to the waste elimination project."

\subsection{Impact on Performance}

After about sixty days, as a result of the implementation, the previously worsening lead time and customer return performance had subsided and began to improve slightly. After six months, BPC's production lead-time reduced by more than 50\%, which was the lowest among its major competitors. Improvements were attributed to major reductions in setup times, resulting in smaller batches and reduced WIP inventory. Due to the various mistake-proofing systems installed in the order fulfillment system, fewer mistakes in order writing and production processes resulted in fewer delivery mistakes (see Table 1). 


\section{Implications for Lean Implementation}

There are three implications of this Lean improvement effort involving soft OR practices or SSM. First, when problem was clearly identified, SSM application in eliminating waste did proceed smoothly. Learning was exciting, many changes were implemented, and the rate of improvements showed an upward trend. Later, when the problem was not clearly identified, SSM application did not proceed smoothly. Learning was no longer exciting, and although changes were implemented, the rate of improvement reached a plateau. This slowdown in improvements had to be handled carefully to prevent improvement failures. Chakravorty (2010, R6) wrote that many improvement programs:

\footnotetext{
“...typically start off well, generating excitement and great progress, but all too often fail to have a lasting impact as participants gradually lose motivation and fall back into old habits. ... We found that when confronted with increasing stress over time, these programs react in much the same way a metal spring does when it is pulled with increasing force - that is, they progress though "stretching" and "yielding" phases before failing entirely. In engineering, this is known as the "stress-strain curve," and the length of each stage varies widely by material."
}

More research is necessary to find out why many improvement programs fail. It is imperative that companies fully understand the reasons for improvement failures. Lean implementation is an expensive undertaking, and without understanding the reasons of improvement failures, companies may abandon the implementation prematurely without realizing optimum benefits from such an implementation.

Second, there is substantial confusion when selecting Lean or Six Sigma for different operations. Lean emphasizes Soft OR practices (e.g., SSM) and, in contrast, Six Sigma promotes hard OR practices (e.g., statistical analysis). In early stages of improvement, when the operations are messy and variables are unknown, Lean is more appropriate. In the later stages of improvement, when the operations are streamlined and variables are known, Six Sigma is more suitable. In fact, in an aircraft manufacturing and repair operations, Chakravorty (2011) found that in division A, Six Sigma was a failure; however, in division B, Six Sigma was a success. The reason for Six Sigma's success was because this division had implemented Lean prior to Six Sigma. The logic is not very hard to understand. For example, after applying SSM repeatedly and removing the clutter or streamlining material flow, let us say that it is determined that Heat treatment requires an unusually long processing time $(\mathrm{Y})$. Then, independent variables (e.g., $\mathrm{X}_{1}$ and $\mathrm{X}_{2}$ ) can be identified, which may impact the dependent variable $\mathrm{Y}$. To determine main and interaction effects, a statistical model $\left(Y=\left\{\beta_{0}+\beta_{1} X_{1}+\beta_{2} X_{2}+\beta_{3} X_{1} X_{2}\right\}\right)$ can be developed, and 
appropriate actions can be taken to reduce the processing time. However, more research is necessary to support the claim that Lean should be implemented before Six Sigma.

Third, in this implementation we experienced substantial difficulty in identifying and prioritizing improvement projects specifically aligned to overall improvement objectives. In order to prioritize improvement projects, two parameters, reduced lead times and improved quality, along with input from workers and management was utilized. Businesses prioritize projects haphazardly, and it is not surprising to find that many projects do not achieve their overall business objectives. To prioritize improvement projects, research from academia has focused on applying hard OR practices or building mathematical models. However, very few or none of these models have been tested in real word operations. Consequently, we do not know the effectiveness of these models. According to Chakravorty (2012, p.32):

“... sophisticated mathematical models, such as ant colony optimization or multicriteria optimization models, clearly enhance one's understanding of how to correctly prioritize improvement projects. Most practicing managers, as in this company, lack the mathematical proficiency necessary to appreciate these models. At the same time, academicians hesitate to test these models in real-world operations. There is no doubt that research in developing or fine tuning mathematical models is necessary. It is also important to recognize that these models need to be tested in the real-world operations. People need to know what works and what does not work in these models in order to create a repository of experiential learning. In doing so, academicians will develop better appreciation of the complexity of managerial decision making and practicing managers will develop a better understanding of sophisticated mathematical models."

There is gap in the communication of academic research to practitioners. Interpreting or applying mathematical models in real-world operations can be very worthwhile. More research is necessary to determine how to correctly identify and prioritize improvement projects in order to align them with the overall improvement objectives.

\section{References:}

Beasley, J.E. 2002. OR-Notes available at: http://people.brunel.ac.uk/ mastjjb/jeb/or/softor.html

Chakravorty, S.S., 2012. Prioritizing Improvement Projects: Benefit \& Effort (B\&E) Analysis, Quality Management Journal, v19, i1, $24-33$. (http://asq.org/pub/qmj/ )

Chakravorty, S.S., 2011. Natural Selection, Quality Progress, v44, i10, 30-35.

(http://asq.org/qualityprogress/past-issues/index.html?fromYYYY=2011\&fromMM=10\&index=1 )

Chakravorty, S.S., 2010. Where Process-Improvement Projects Go Wrong, The Wall Street Journal (in collaboration with MIT Sloan Management Review), r6, January 25.

(http://online.wsj.com/public/page/business-insight.html)

(http://sloanreview.mit.edu/executive-adviser/2010-1/ )

Chakravorty, S.S., 2009. Process Improvement: Using Toyota A3 Reports, Quality Management Journal, v16, i4, 7-26.

(http://asq.org/pub/qmj/past/vol16 issue4/index.html ) 
Chakravorty, S.S., Hales, D.N., 2008. An Evolution of Manufacturing Cells: An Action Research Study, European Journal of Operational Research, v 188, 153-168.

Checkland, P. 1999. Soft Systems Methodology: A Thirty-Year Retrospective. Systems Research and Behavioral Science, v17, 11-58. .

Heyer, R. 2004. Understanding Soft Operations Research: The Methods, their Application and its Future in the Defense Setting, DSTO Information Sciences Laboratory, Edinburgh, South Australia.

http://www.dsto.defence.gov.au/publications/3451/DSTO-GD-0411.pdf

Liker, J.K., 2004. The Toyota Way, Mc Graw-Hill, New York, NY.

Mingers, J. 2011. Soft OR Comes of Age - but not everywhere! Omega, v39, i6, 729-741.

Ohno, T., 1988. Toyota Production System: Beyond Large Scale Production System. Productivity Press. Portland.

Paucar-Caceres, A. 2010. Mapping the Changes in Management Science: A Review of 'Soft' OR/MR Articles in Omega (1973-2008). Omega, v38, i1-2, 46-56.

Pidd, M., 2003. Tools for Thinking: Modeling in Management Science, John Wiley, New York, NY.

Reisman, A., Oral, M., 2005. Soft Systems Methodology: A Contest Within a 50-Year Retrospective of OR/MS, Interfaces, v35, i2, 162-178.

Royston, G., 2011. Meeting Global Health Challenges through Operations Research and Management Science, Bulletin of the World Health Organization, v89, 683-688.

Shingo, S., 1985. The Revolution in Manufacturing: The SMED System. Productivity Press, Portland, OR.

Shingo, S., 1986. Zero Quality Control: Poka-Yoke System. Productivity Press. Portland, OR.

Shingo, S., 1987. The Sayings of Shigeo Shingo: Key Strategies for Plant Improvement. Productivity Press,

Portland, OR.

Shingo, S., 1988. Non-Stock production: The Shingo System for Continuous Improvement. Productivity Press.

Portland, OR.

Spear, S. Bowen, H.K. 1999. Decoding the DNA of the Toyota Production System. Harvard Business Review, v177, i5, 96-107.

Womack, J.P., Jones, D.T., 2003. Lean Thinking. Free Press, New York, NY.

Notes:

1. www.shingoprize.org

2. www.asq.org/le

3. www.lean.org

Table 1

Performance before and after implementation

\begin{tabular}{lll}
\hline Measures & $\begin{array}{l}\text { Before } \\
\text { Implementation }\end{array}$ & $\begin{array}{l}\text { After } \\
\text { Implementation }\end{array}$ \\
\hline Lead-time & 5.8 weeks & 2.2 weeks \\
Delivery mistakes & $4 \%$ & $1 \%$ \\
Orders active on floor* & 49 & 9 \\
\hline
\end{tabular}

*=provides an indication of work-in-process (WIP) inventory

Figure 1

Progression of Soft System's Methodology (SSM) Implementation 


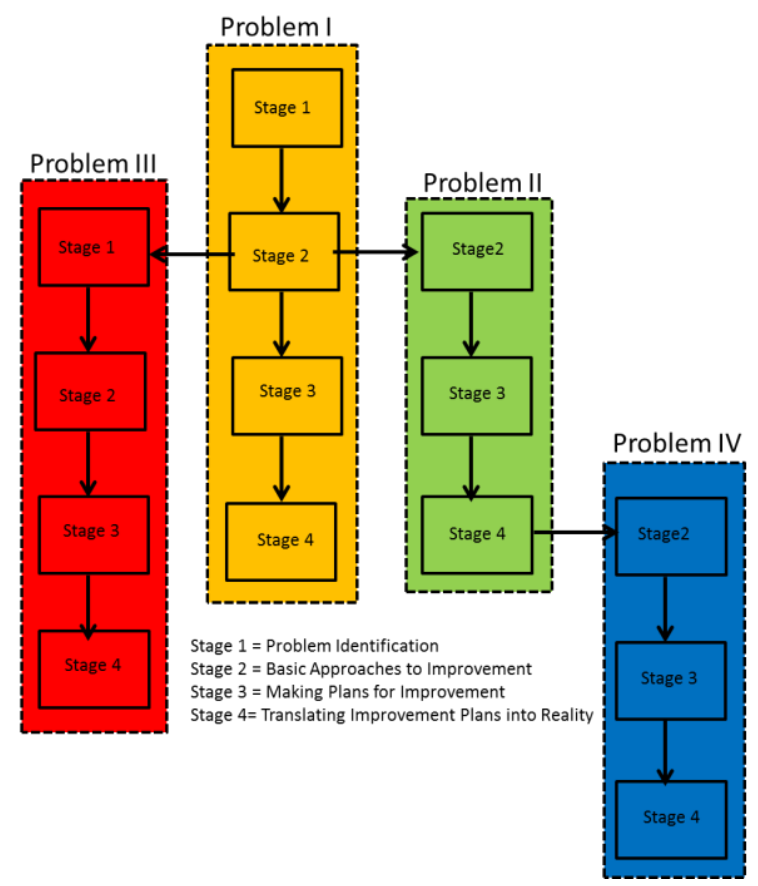

Appendix I

Application of Soft System's Methodology (SSM) to develop mistake proofing and quick changeover systems

\section{Problem I}

Stage 1: Problem Identification

The team was aware that many production orders were delivered incorrectly at the jobsite. Further analysis of the customer complaints reports reveled that over $7 \%$ of the orders were incorrectly delivered. The team identified two key customers with most of the customer complaints, and interviewed them extensively. The interviews revealed that most of the orders, which are delivered incorrectly to the jobsite, were written correctly. The team studied production orders related to those customer complaints, and found that those orders were indeed written correctly. The team knew that the source(s) of the problem existed between shipping and production. The team decided to work backwards from the driver's report in order to gather information.

Stage 2: Basic Approaches to Improvement

The team studied the driver report and found that there were many instances of multiple deliveries for the same order. The reason was that the dispatching system was using outdated map coordinate system. The experienced dispatchers had mentally corrected the coordinates; however inexperienced dispatchers made many mistakes in delivering an order. In order to receive additional insights, many members of the team rode with the drivers. Several drivers believed that many orders were being incorrectly delivered because either production built the order incorrectly or the order was not at the designated place. They also acknowledged that the drivers made mistakes in pulling a production orders.

The team wanted to investigate this further (see, Problem II, Stage 2). The team found that a considerable amount of confusion existed in dispatching because order delivery times were frequently moved (e.g., 1:00 PM to 3:00 PM) by outside sales. This confusion was contributing to sending many orders to the wrong jobsite. Since no data was available, the team collected data by observing the process for a day, and the observation reveled that about $30 \%$ of the jobs were altered. Further analysis revealed that orders that included doors were late due to long setup time at the door shop. The team wanted to investigate this problem simultaneously (see, Problem III, Stage 1).

Stage 3: Making Plans for Improvement

The team brainstormed and generated many solutions. Many suggested purchasing the latest map coordinates and with an option of receiving frequent updates. Some suggested that each salesperson should be allowed to alter a fixed percentage of daily orders scheduled for delivery. The team carefully evaluated the possible solution ideas. Given the competitive situation and the 
declining customer service, the team rejected the idea of limiting the number of changes allowed in the schedule for delivery. The team evaluated the new map coordinates and approved the purchase of new system.

Stage 4: Translating improvement plans into reality

The team took dispatchers' and drivers' opinions into consideration when fine tuning the map coordinate requirements. To smooth the transition process, several trial runs were performed before the actual installation of the system. As the dispatchers and drivers wanted the change, there was no resistance to change.

\section{Problem II}

Stage 2: Basic Approaches to Improvement

The team gathered information on the daily production operations and after considerable analysis, deliberation, and reflection, discovered two problems. First, there was no designated place for the finished goods at the end of production line. Second, the drivers were making mistakes in pulling the orders because it was difficult to find the order on the production floor.

\section{Stage 3: Making Plans for Improvement}

The team brainstormed to generate solution ideas. The team deliberated to determine a place for finished goods and raw material. Many suggested that warehouse floor space be allocated for both finished goods and raw material. Many others suggested that trolleys be purchased for stacking finished goods. The team carefully evaluated the solution ideas. First, the team found that neither finished goods nor raw material could be placed on the floor. The door units are heavy and they need to be kept in a reclined position. In order to keep the doors in a reclined position, the team considered purchasing steel shelves. The team rejected idea because that the steel shelves were expensive, material flow was difficult, and future expansion was not possible. The team evaluated trolleys and found them relatively inexpensive, and decided to purchase those.

\section{Stage 4: Translating improvement plans into reality}

The team took production workers' and driver's opinions into consideration to refine the size and the number of trolleys. To smooth the transition process, a few trolleys were purchased and tried in daily production runs. Once it was found that trolleys were working well, additional trolleys were ordered. Although purchasing the trolleys eliminated many mistakes by the production workers and the drivers, there were still many mistakes being committed in pulling and order. However, the team confirmed that there was a decline in customer complains and now $4 \%$ of the orders were incorrectly delivered. The team was encouraged by the results, and decided to gather information needed to continue mistake proofing the order pulling process (See, Problem IV, Stage 2).

\section{Problem III}

Stage 1: Problem Identification

The door shop machine had a setup time of about 20 minutes. In order to gather information on the setup time, the team studied the machine operation.

\section{Stage 2: Basic Approaches to Improvement}

The team observed the machine operation and organized the setup time into external and internal setups. External setup can be performed while the machine is not running, and consists of the following activities. Door slabs must be picked from raw material inventory and staged at the door loader prior to entering the production cycle. Door slabs are assembled into order stacks according to production priority. The stacks are set in place at the door loader. Internal setup can only be performed while the machine is running and consists of the following activities: The loader picks up individual doors and sets them in place on the production line conveyor. The slab is loaded into the door machine. The operator loads hinge and strike jambs into the door machine and hits a button to begin the automatic routing process. During this process, the operator loads each hinge applicator by hand. After the machine process is completed, the operator pulls jambs and the slab out of the machine. Further analysis reveled that external setup was about $90 \%$ of the total setup time. There were two problems associated with external setup. First, door slabs often were not picked from the raw material inventory before the machine ran out of door slabs. This was because the door slabs were fed by a forklift, which was also shared by the Receiving Department to unload vendors' trucks. Over time, as business picked up, the forklift got busy in unloading the vendors' trucks and the door shop starved for door slabs. Second, the supervisor of the door shop conceptually explained how the internal setup of the machine could be improved, but the team wanted to make sure that the suggested changes did not impact other parts of the machine and wanted to involve the vendors of the machine.

\section{Stage 3: Making Plans for Improvement}

The team deliberated to generate possible solutions. As external setup was a significant portion of the entire setup, the team decided to focus its efforts on eliminating the external setup. In order to pick up door slabs from the raw material inventory, the team suggested the purchase of a forklift and argued that the same forklift could also be used by other shops. Another possible solution was to hire a semi-skilled worker who would pick up the door slabs trolleys from the raw material inventory. In addition, the team learned that machine vendors had shortened the internal setup by $70 \%$ and improved the processing of doors by $50 \%$ in their latest model, and were eager to sell the new model. The team carefully evaluated each possible solution. The supervisor of the door shop provided justification for a forklift. The team carefully evaluated and found that they could not 
justify purchasing a forklift at the time, given the volume of business. The team found that they could justify hiring a semiskilled worker and purchasing some trolleys, so they approved these decisions. The supervisor of the door shop was not very pleased with this decision. The team evaluated the possibility of buying a new machine and determined that a new door machine was not required at the time, based on the projected next two years demand for doors. Since the door supervisor had ideas for improvement in the existing machine, the team contacted the vendors to send a design engineer to supervise the changes. Despite several requests, the vendors did not agree to send an engineer. The team did not want to take a risk and discarded the idea.

Stage 4: Translating improvement plans into reality

The team considered the door shop supervisor's and workers' opinions made to fine tune the external setup elimination process. Many trial runs were performed painstakingly to make sure the process was working smoothly. Initially, the team did not encounter any resistance to accepting the new ideas. However, after some time, the team found that the door shop supervisor was neither using the semi-skilled workers nor the trolleys provided to him for feeding the door shop. The team held a meeting with the supervisor and found out that he was rejecting the idea because the team had rejected his idea. The team approached the problem differently by organizing a casual meeting between customers and the door shop supervisor. Customers discussed how they were receiving incorrect orders at the jobsite, and the team related the problem to long setup times at the door shop. After hearing the problems from the customers, the door shop supervisor decided to implement the solution ideas. As the door shop implemented the new solution ideas, the setup time for the door shop gradually declined, and additional capacity was generated. After several weeks, the supervisor of the door shop reported that setup time had significantly declined. The setup time was only 2 minutes, which also improved the productivity of the shop by $20 \%$.

\section{Problem IV}

Stage 2: Basic Approaches to Improvement

In order to gather information, the team interviewed man many drivers and door shop workers. The production workers said that drivers were impatient and did not look hard in the trolleys to pull an order together. The drivers said that it is hard to differentiate each order and blamed the production workers for not being organized when stacking the orders. After deliberation and reflection, the team suspected that the root problem was that production orders came in different sizes and many times it was not possible to stack one complete order on a trolley, therefore, multiple trolleys were used to stack the complete order, which separated the order.

\section{Stage 3: Making Plans for Improvement}

The team brainstormed to generate solutions. The teams considered purchasing different sizes of trolleys or keeping large orders on the production floor. The team also considered a unique color label for each order. In this manner, the existing trolleys could be used to stack orders on two trolleys. The team carefully evaluated the solution ideas. The team found that different sizes of trolleys were available from the vendors, and there was not much difference in prices from one size to the other. The team rejected the idea because even if the completed orders can be stacked on the trolleys, this did not help the drivers to mistake=proof their order pulling process. The team concentrated their efforts on evaluating unique color labels for each order. This was considered a good idea because it was easy to introduce color label and was easily recognizable by the drivers.

Stage 4: Translating improvement plans into reality

The team considered opinions of order writers, dispatchers, production workers, and drivers in order to fine tune the color labeling concept. As several departments were impacted, many trial runs were painstakingly performed to debug the process. This took a long time and many employees were frustrated and expressed their disagreement openly. Some suggested the purchase of different sizes of trolleys to continue the status quo. Initially, the team encountered a lot of resistance to accepting the new idea and, in fact, many workers and drivers tried to sabotage the process. The team diligently continued to implement, held meetings with the disgruntled workers, and demonstrated the usefulness of color labels to mistake-proof the order pulling process. As many drivers used the new color labels, they found that they could easily pull an order. The drivers were saving considerable amount of time, and there was not much friction between drivers and workers. Over time, the drivers and production workers got used to the new system. An analysis of customer complaint report reveled that complaints had significantly declined and only less than $0.5 \%$ the orders were incorrectly delivered. 